\section{Brazilian Journal \\ of Chemical \\ Engineering}

ISSN 0104-6632

Printed in Brazil www.scielo.br/bjce

Vol. 35, No. 01, pp. 101 - 110, January - March, 2018

dx.doi.org/10.1590/0104-6632.20180351s20160333

\title{
EXPERIMENTAL STUDY OF THE DIFFUSION- CONTROLLED CORROSION OF COPPER IN THE BOTTOM OF A JET STIRRED REACTOR
}

\author{
Mohamed S. Helal ${ }^{1}$, Hassan A. Farag ${ }^{1}$, Moustafa S. Mansour ${ }^{1}$ and Yasmine O. Fouad ${ }^{1, *}$ \\ ${ }^{1}$ Chemical Engineering Department, Faculty of Engineering, Alexandria University, Egypt
}

(Submitted: May 18, 2016; Revised: September 28, 2016; Accepted: October 12, 2016)

\begin{abstract}
Jet stirred tank reactors are usually preferred to mechanically stirred tank reactors in the case of high pressure stirred tank reactors in order to avoid the mechanical problems inherent with mechanically agitated reactors. Owing to the impact force exercised by the fluid jet on the tank bottom, the tank bottom is subjected to severe corrosion. The aim of the present work is to address this problem using an accelerated system which simulates natural diffusioncontrolled corrosion of metals. Diffusion-controlled corrosion of a fixed copper disc, at the bottom of a cylindrical tank, under a single phase forced jet flow of acidified dichromate solution was investigated. Variables studied were: physical properties of the solution, solution velocity through different diameters of jet nozzle, distance between the jet outlet nozzle and the copper disc surface; and the effect of using a drag reducing polymer. An overall correlation was obtained: $S h=0.579 S c^{0.33} R e^{0.975}(h / d)^{0.049}$ valid for $850<S c<1322,1852<R e<5000$ and $0.3<h / d<1.2$. Addition of polyethylene oxide as a drag reducing polymer was found to diminish the rate of corrosion under single phase forced jet flow by an amount depending on the operation conditions.
\end{abstract}

Keywords: Jet reactor, mass transfer, jet impinging on a flat plate, submerged jet, diffusion controlled corrosion, drag reducing polymer.

\section{INTRODUCTION}

Unit operations are numerous and diverse, one of the most common in chemical industrial processes being mixing. The role of mixing is to homogenize the different materials used and to boost the heat transfer, the mass transfer and the rate of chemical reactions between the different species and phases. Various mixing techniques used in engineering practice include mechanical stirring using a rotating impeller, jet mixing and static mixing. Since the impinging jets are able to escalate the mixing process efficiently, they have been widespread in industrial applications including cooling, heating and drying (Shi et al., 2015) and high pressure stirred tank reactors. In this last case the use of jet mixing instead of mechanical mixing obviates the mechanical problems associated with mechanical stirring such as the need for expensive stuffing boxes and other sealing systems. Impinging jets are widely used in engineering applications as they offer the highest mass and heat transfer in the impingement zone; also, multiple parameters can efficiently control the transfer coefficients, such as the nozzle shape, the jet array assembly using multiple jet configurations, the nozzleto-plate distance, Reynolds number of the flow, external forcing, imposed swirl, etc. (Sergey et al., 2007). Vickers (1959) referred to the critical Reynolds number, Re, based on the nozzle diameter, as 1000. McNaughton and Sinclair (1966) supported his finding and reported having observed four characteristic jet patterns: i) What they call a "dissipated laminar jet", $\operatorname{Re}<300$. ii) Fully laminar jet, 300 $<\operatorname{Re}<1000$. iii) Semi-turbulent jet, that starts as a laminar jet, eventually becoming turbulent, $1000<\operatorname{Re}<3000$. iv) 
Fully turbulent jet, $\operatorname{Re}>3000$. The above observations were made on liquid into liquid jets, in different shape vessels, using as a tracer methylene-blue dye. Very similar results were obtained by Hrycak et al. (1970) who worked with an air jet. The above results are also in line with the observations made by Cederwall (1953) who found that jets with $\operatorname{Re}>3000$ are already turbulent.

The benefit offered by impinging jet flow is a high, localized mass (or heat) transfer rate as in the stagnation region only thin hydrodynamic and concentration (or thermal) boundary layers are formed. These boundary layers can be of tens of microns thick (Chen et al., 2000). Engineering applications using impinging jets include turbine blade cooling, metal annealing, textile drying (Choo et al., 2016), high temperature gas turbine cooling systems, cooling of electronic components, drying of wood, paper and film industries, treatment of glass, tempering of metals and plastic plates, and more recently, industrial food processing (Şara et al., 2008).

The impinging jet can be perceived as a combination of many different flow modules, namely a free turbulent jet, stretched vortices in a curved shear layer, a stagnation flow and a wall jet, with each portion of the flow having its own distinctive characteristics (Ho and Nosseir, 1981) as shown in Fig. 1.

Sydberger and Lotz (1982) deduced that most industrial corrosion processes take place under diffusion or under mixed diffusion and chemical control conditions. Either under diffusion or mixed controlled conditions a mass transfer correlation is essential to calculate the solid liquid mass transfer coefficient to be able to anticipate the corrosion rate and the corrosion allowance in the design stage (Sedahmed et al., 1998).

Metal corrosion includes two concurrent reactions, specifically an anodic reaction during which the metal dissolves $\left(\mathrm{M} \rightarrow \mathrm{M}^{2+}+2 \mathrm{e}\right)$, and a cathodic reaction where a depolarizer (such as dissolved oxygen) is reduced $\left(1 / 2 \mathrm{O}_{2}+\right.$ $\left.\mathrm{H}_{2} \mathrm{O}+2 \mathrm{e} \rightarrow 2 \mathrm{OH}^{-}\right)$. These two reactions are heterogeneous, involving a mass transfer step. The metal ions should diffuse away from the metal surface; meanwhile, dissolved oxygen has to diffuse from the bulk of the solution to the surface of the corroding metal in the $\mathrm{pH}$ range 4-10 which is frequently used in practice (Fontana, 1987).

Under certain conditions, dissolved oxygen and dissolved metal ions have to diffuse across a porous film of corrosion product, e.g., an oxide covering the metal surface (Zahran and Sedahmed, 1998).

Gregory and Riddiford (1960) proposed a technique for the measurement of the liquid transport coefficient in the mass transfer step between a liquid and a solid surface, which is the copper dissolution method. The method comprises the contact of a solution of sulphuric acid containing potassium dichromate with a copper surface. The dichromate anion acts as an oxidizing agent and oxidises the copper according to the following overall equation:
In the four decades following this first publication, significant improvement in utilizing this technique has been cited in the literature and the main variables of the system, e.g., the diffusion coefficient of the dichromate ion, are finally settled (Gruber and Melin, 2003).

This is the reason for choosing this technique for the liquid transport coefficient calculation. The aim of the present work is to study the effect of a jet forcing flow on the rate of diffusion controlled corrosion of a stationary copper disk in relation to the following parameters: solution velocity by changing outlet nozzle diameter $(\mathrm{Vn}$, $d n)$, physical properties of the solution $(\rho, \mu$, and $D)$, jet distance between the disc surface and flow inlet nozzle (h).

The second objective of the present study is to examine the effect of Polyox-301 drag reducing polymer on the rate of mass transfer in the jet reactors. Drag-reducing agents are being used in practice to reduce the pumping power in turbulent flow systems due to their ability to decay the energy-dissipating small-scale high-intensity eddies which prevail in the turbulent hydrodynamic boundary layer (Sellin et al., 1982a; Sellin et al., 1982b). Hence, it is expected that drag-reducing polymers will reduce the rate of mass transfer in jet reactors through the increase of the diffusion layer thickness. The degree to which the rate of mass transfer in jet reactors is decreased by drag-reducing polymer will be examined in the present work. This can help in judging the economic feasibility of using drag-reducing polymers in jet reactors involving diffusion-controlled processes. No studies on the effect of drag-reducing polymers on the rate of mass transfer in jet reactors have been reported.

\section{MATERIALS AND METHODS}

\section{Experimental setup}

The experimental apparatus used in the present work is shown in Fig. 2. It consists of a cylindrical Plexi glass container with inner diameter $10 \mathrm{~cm}$ and $50 \mathrm{~cm}$ in height, a copper disk $10 \mathrm{~cm}$ in diameter and $0.5 \mathrm{~cm}$ in thickness and a plastic centrifugal pump $(0.5 \mathrm{hp})$. A PVC piping system of different diameters was used to connect the tank and the pump. The copper disc is fitted well at the bottom of the tank; the upper side of the disc faces the flow while the bottom side was well coated by epoxy resin. The flow rate was adjusted by the main valve to the maximum flow during all experiments. The copper disk was replaced each run by a new similar one.

\section{Procedure}

In preparing all solutions A.R grade chemicals and distilled water were used. All runs were carried out at temperature $28 \pm 2^{\circ} \mathrm{C}$. Before each run 2 liters of freshly

$$
3 \mathrm{Cu}+\mathrm{K} 2 \mathrm{Cr} 2 \mathrm{O} 7+7 \mathrm{H} 2 \mathrm{SO} 4 \rightarrow 3 \mathrm{CuSO} 4+\mathrm{K} 2 \mathrm{SO} 4+\mathrm{Cr} 2(\mathrm{SO} 4) 3+7 \mathrm{H} 2 \mathrm{O}
$$




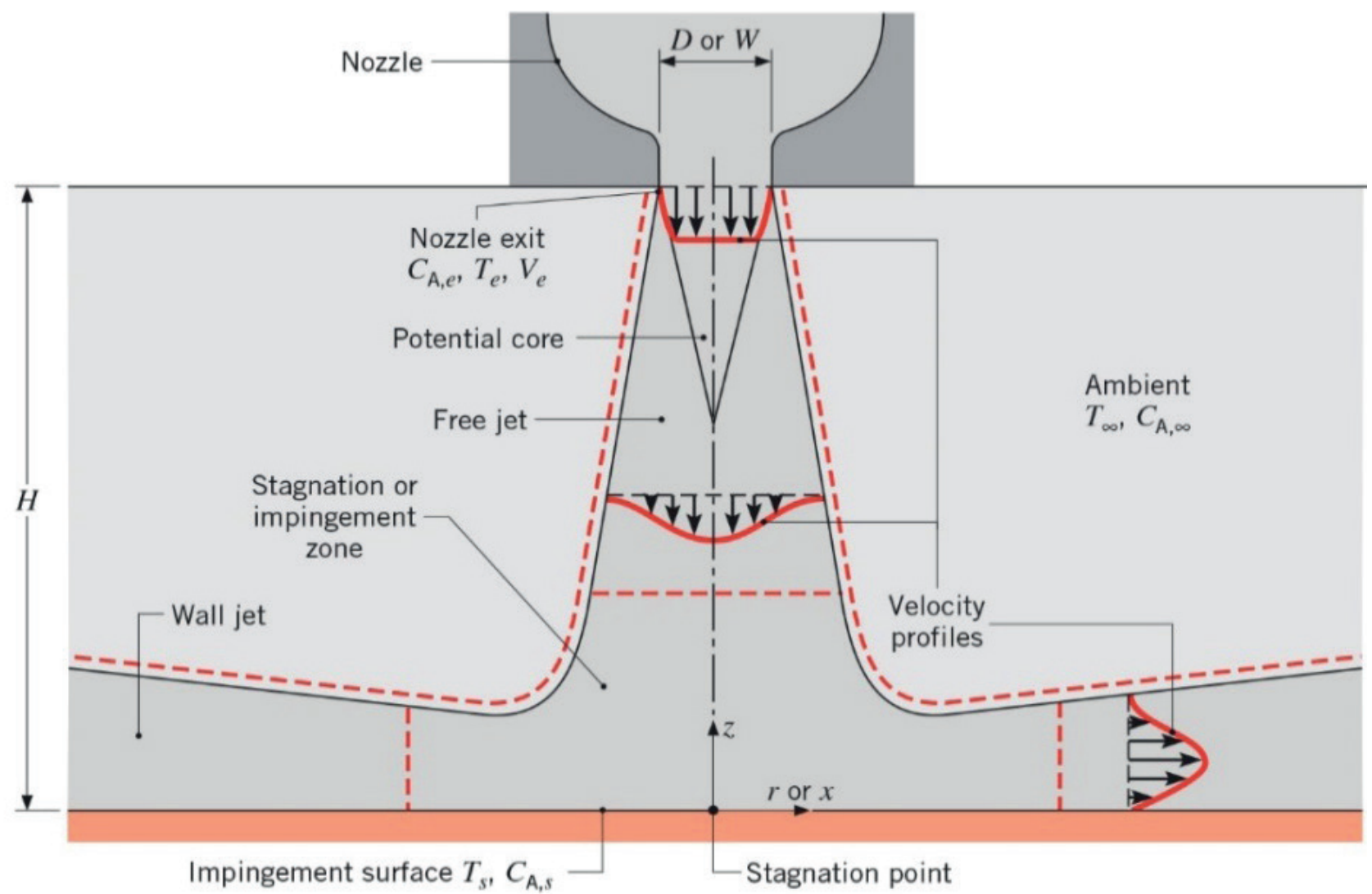

Figure 1. Surface impingement of a single round or slot jet [7].

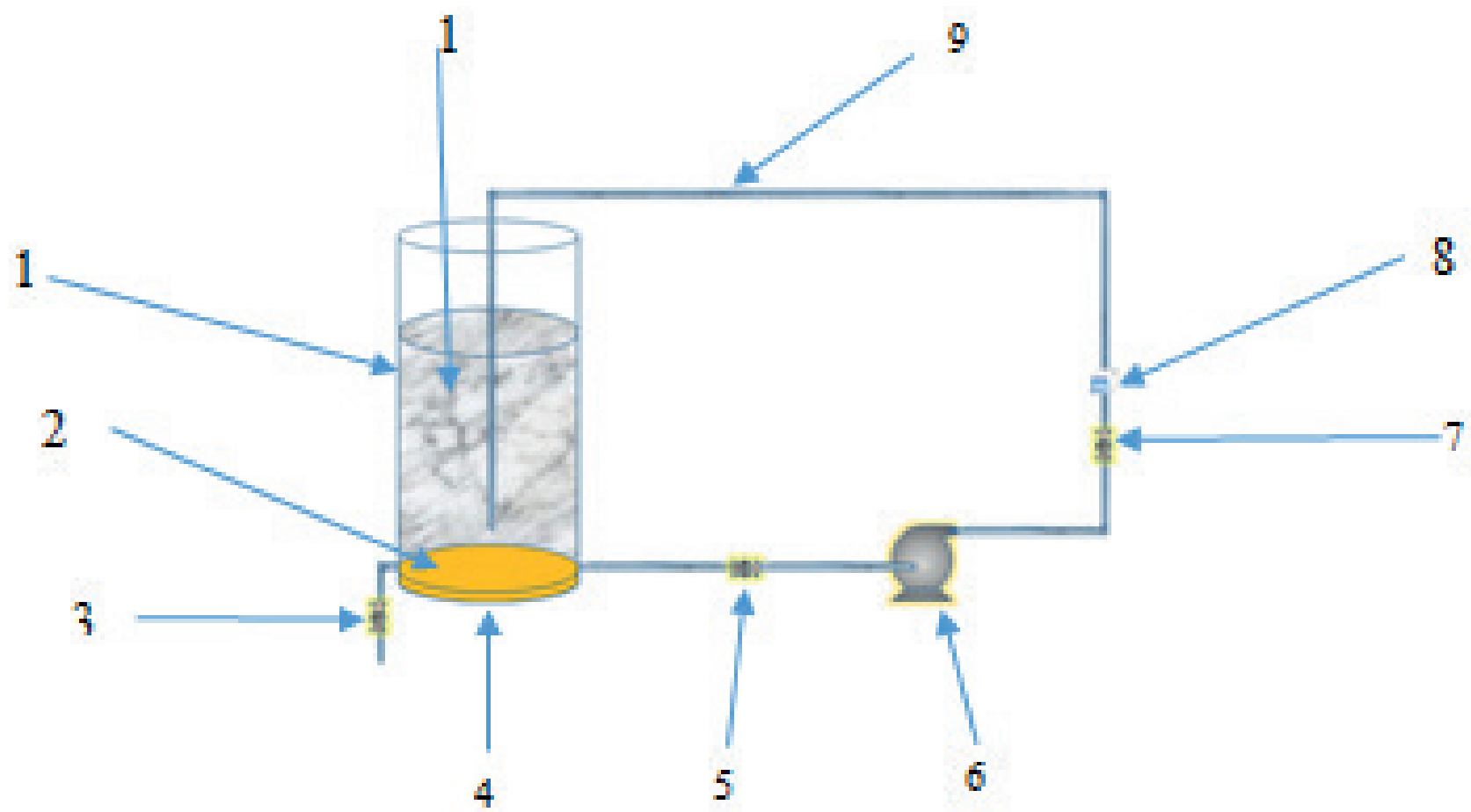

Figure 2. Experimental setup: 1-Plexiglass tank; 2- Copper disc upper side; 3- Sample drain; 4- Copper disc bottom side; 5- Plastic valve; 6Plastic head centrifugal pump; 7- Plastic valve; 8- Discharge line flow meter; 9- Inlet line to tank; 10-Acidified Dichromate solution 
prepared acidified dichromate solution were placed in the holding tank. The flow rate of the solution was adjusted to the maximum value and was measured with a graduated cylinder and stopwatch during each run. Samples of the solution $\left(5 \mathrm{~cm}^{3}\right)$ were withdrawn from the tank at 5 minute intervals for dichromate analysis by titration against standard solution of ferrous ammonium sulfate using diphenyl amine barium salt as indicator (Vogel, 1977). During each run, the temperature was measured accurately. Solution density and viscosity required for data correlation were measured by a density bottle and an Ostwald viscometer, respectively, while the solution diffusivity (D) was taken from the literature (Gregory and Riddiford, 1960) and was corrected for the change in temperature using the Stokes-Einstein equation. Table 1 shows the physical properties of solutions used in the present work. The investigated parameters are the solution velocity, that ranged from 7.89 to $34.2 \mathrm{~cm} / \mathrm{s}$; the nozzle diameter, three diameters were tested: $1.27,1.905$ and $2.54 \mathrm{~cm}$; the nozzle-to-disc distance, the distances inspected were 3, 6, 9 and $12 \mathrm{~cm}$; the sulfuric acid concentration: $0.5 \mathrm{M}, 1 \mathrm{M}$ and $2 \mathrm{M}$ were used and finally the concentration of the drag-reducing polymer (Polyox WSR-301), 100, 200, 300, 400 and 500 ppm were added to the solution. Each experiment was repeated three times to achieve precision.

\section{RESULTS AND DISCUSSION}

The mass transfer coefficient of the diffusion-controlled corrosion of the copper disc in acidified dichromate solution was obtained under different conditions from the dichromate concentration-time data. Figure 3 shows that data fit equation (3).

The rate of reaction is given by (Pickett, 1977):

$$
-Q \frac{d C}{d t}=K A C
$$

which yields upon integration:

$$
Q \ln \left(\frac{c_{0}}{c}\right)=K A t
$$

$\mathrm{K}$ was determined by plotting $\ln \left(C_{\mathrm{o}} / C\right)$ vs time under different operating conditions. The slope of the resulting straight line, $\mathrm{KA} / \mathrm{Q}$, was used to calculate the mass transfer coefficient $(K)$.
The present data were correlated by using the method of dimensional analysis.

Dimensional analysis leads to the equation:

$$
\mathrm{Sh}=\mathrm{aRe} \mathrm{Rc}^{\alpha} \mathrm{Sc}^{\beta}(\mathrm{h} / \mathrm{d})^{\gamma}
$$

The constants a, $\alpha$ and $\gamma$ were determined using the present experimental data. Following previous experimental and theoretical mass transfer studies (Sherwood et al., 1975; Pickett, 1977; Sedahmed et al., 1998; Abdel-Aziz et al., 2010), the value of $\beta$ used was 0.33 .

Figure 3 shows that, as the nozzle diameter is decreased, the value of $\mathrm{K}$ increases.

The decrease in the nozzle diameter increases the mass transfer coefficient due to the increase in the jet velocity emerging from the nozzle, leading to decreasing the thickness of the diffusion boundary layer with a consequent increase in $\mathrm{K}$.

$$
\mathrm{K}=\mathrm{D} / \delta
$$

where $\mathrm{D}$ is the diffusivity; $\delta$ is the diffusion layer thickness.

Fig. 4 shows the effect of Re on Sh at different Sc; the data fit the following equation:

$$
\mathrm{Sh}=\mathrm{a} \operatorname{Re}^{0.975}
$$

Fig. (4) also shows that for a given Re, Sh increases with increasing $\mathrm{Sc}$ in accordance with the hydrodynamic boundary layer theory (Bergman et al., 2011).

The high Re exponent 0.975 may be due to the increase in turbulence intensity as a result of the stronger exchange of momentum with the surrounding recirculating flow; this result is consistent with similar previous mass transfer studies performed by Rao and Trass (1964) and Chin and Tsang (1978). However, Rao and Trass (1964), who used a technique based on the dissolution of a benzoic acid surface in water, obtained a higher Re exponent, 1.06. The high Re exponent obtained by Rao an Trass maybe ascribed to the tendency of benzoic acid particles to be removed by attrition in addition to dissolution, thus giving an exaggerated rate of mass transfer, especially at low nozzle to plate distance and high Reynolds number.

\begin{tabular}{|c|c|c|c|c|}
\hline $\begin{array}{r}\text { Solution } \\
\text { composition }\end{array}$ & $\begin{array}{l}\text { Density } \\
\rho \\
\left(\mathrm{kg} / \mathrm{m}^{3}\right)\end{array}$ & $\begin{array}{c}\text { Viscosity } \\
\mu \\
(\mathrm{kg} / \mathrm{m} . \mathrm{sec})\end{array}$ & $\begin{array}{c}\text { Diffusivity } \\
D \\
\left(\mathrm{~m}^{2} / \mathrm{sec}\right) \times 10^{10}\end{array}$ & $\mathrm{Sc}$ \\
\hline $0.03 \mathrm{M} \mathrm{K}_{2} \mathrm{Cr}_{2} \mathrm{O}_{7}+0.5 \mathrm{M} \mathrm{H}_{2} \mathrm{SO}_{4}$ & 1023.4 & 0.0009273 & 10.654 & 850 \\
\hline $0.03 \mathrm{M} \mathrm{K}_{2} \mathrm{Cr}_{2} \mathrm{O}_{7}+1 \mathrm{M} \mathrm{H}_{2} \mathrm{SO}_{4}$ & 1059.662 & 0.001035 & 9.5458 & 1023 \\
\hline $0.03 \mathrm{M} \mathrm{K}_{2} \mathrm{Cr}_{2} \mathrm{O}_{7}+2 \mathrm{M} \mathrm{H}_{2} \mathrm{SO}_{4}$ & 1116.374 & 0.0012077 & 8.1807 & 1322 \\
\hline
\end{tabular}

This behavior also agrees closely with the published heat transfer data (Pan et al., 1992; Webb and Ma, 1995; Zheng et al., 1997; Wen and Jang, 2003).

Table 1. Physical properties of the solution at different compositions:- 


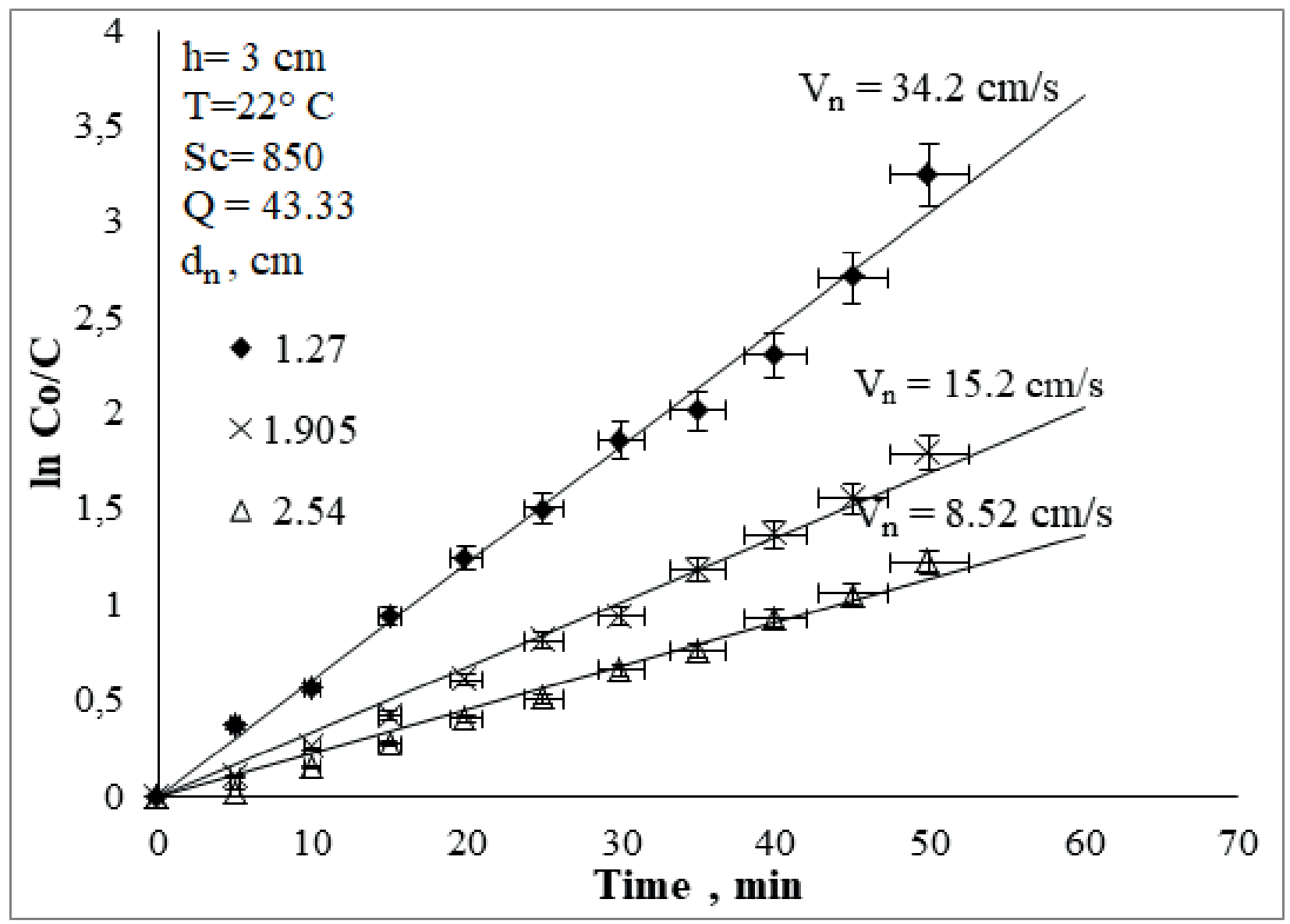

Figure 3. Typical $\ln \mathrm{Co} / \mathrm{C}$ versus $\mathrm{t}$ for the copper flat disc at different solution velocities, showing the error bars

The effect of different $\mathrm{h} / \mathrm{d}$ ratio on Sherwood number was plotted at different Sc values in Fig. 5.

Fig. 5 shows that, for a given Re, decreasing (h/d) increases the Sherwood number at a constant value of the Sc number. This can be attributed to the fact that decreasing the value of $h$ leads to more turbulence at the disc surface. Typically, the jet flow is turbulent and is characterized by a uniform velocity profile at the nozzle outlet. However, as the distance from the exit increases, the momentum exchange between the jet and the ambient fluid causes the free boundary of the jet to broaden and the potential core, where the exit velocity profile is uniform, to contract. Downstream of the potential core the velocity profile is non-uniform over the whole cross section of the jet and the maximum velocity decreases with increasing distance from the nozzle exit (Bergman et al., 2011).

The obtained data fit the equation:

$$
\operatorname{Sh} \alpha(\mathrm{h} / \mathrm{d})^{0.049}
$$

In view of the above results, an overall mass transfer correlation was envisaged in terms of the dimensionless groups $\mathrm{Sh}, \mathrm{Re}$ and (h/d). Fig. 6 shows that the present data for the conditions $850<\mathrm{Sc}<1322,1852<\operatorname{Re}<5000$ and $0.3<(\mathrm{h} / \mathrm{d})<1.2$ fit the equation:

$$
\mathrm{Sh}=0.5789 \mathrm{Re}^{0.975} \mathrm{Sc}^{0.33}(\mathrm{~h} / \mathrm{d})^{0.049}
$$

with an average deviation of $\pm 18 \%$. It is noted that, under the present range of experimental conditions, the above equation represents the flow field of an impinging jet, including transitional and turbulent zones (McNaughton and Sinclair, 1966).

Equation 8 can be used in practice to predict the rate of diffusion-controlled corrosion of a steel bottom under jet impinging flow where the rate of corrosion is controlled in the $\mathrm{pH}$ range of 4-10 by the rate of mass transfer of dissolved oxygen from the bulk solution to the corroding surface of the steel (Fontana, 1987).

It would be instructive to compare the present data with previous mass transfer data in the literature;

Sedahmed et al. (2007) studied the rate of mass transfer at the interface between an aqueous layer and a mercury pool upon which an axial turbulent jet was impinging, under the conditions: $3000 \leq \mathrm{Re}_{\mathrm{n}} \leq 25000,1740 \leq \mathrm{Sc} \leq$ $2565,3 \leq \mathrm{H} / \mathrm{d}_{\mathrm{n}} \leq 245.5 \leq \mathrm{d} / \mathrm{dn} \leq 22$, and Their data were correlated by the equation: 


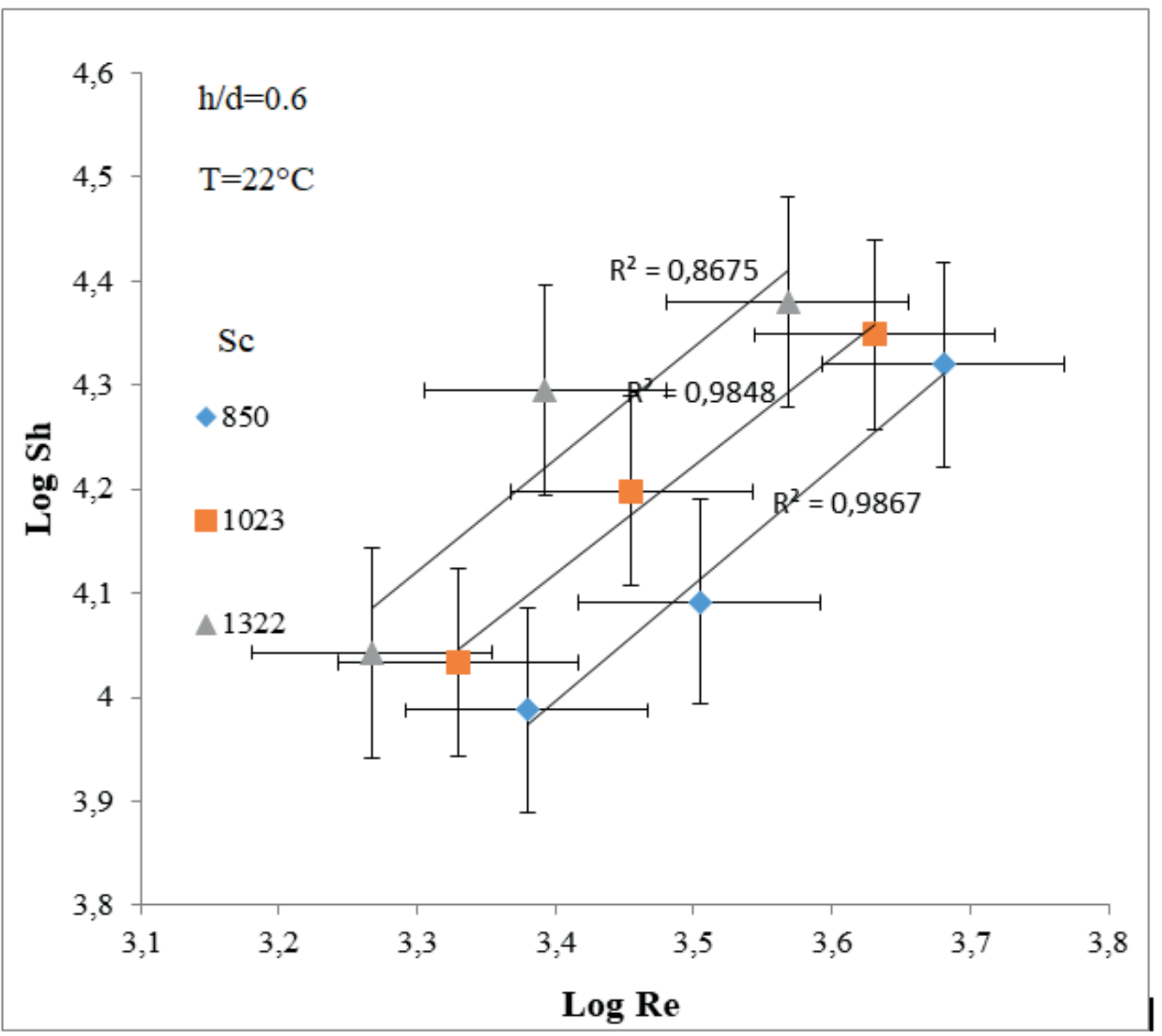

Figure 4. Log Sh vs. Log Re at different Sc values using a constant dimensionless nozzle height, showing the error bars

$$
\mathrm{Sh}=0.043 \mathrm{Sc}^{0.33} \operatorname{Re}^{1.08}\left(\mathrm{~d}_{\mathrm{n}} / \mathrm{H}\right)^{0.33}
$$

The higher Re dependency obtained in this study compared to a lower value in our work may be attributed to the additional effects induced by using a deformable mercury pool target, such as the formation of a cavity at the impingement location and oscillation of the cavity surface along with the rest of mercury surface.

Konsowa (2010) studied the effect of solution flow rate, initial copper ion concentration, and the axial distance between a zinc disk and submerged jet on the rate of copper ion removal by cementation on a zinc disc from dilute copper sulfate solution in a recirculating batch reactor consisting of a horizontal zinc disc impinged by an axial turbulent submerged jet.

The rate of diffusion-controlled cementation of copper ion was expressed in terms of the mass transfer coefficient; the data were correlated with the dimensionless correlation:

$$
\mathrm{Sh}=0.306 \mathrm{Sc}^{0.33} \mathrm{Re}^{0.997}\left(\mathrm{~d}_{\mathrm{n}} / \mathrm{l}\right)^{0.337}
$$

The Re dependency is in agreement with the present work.

Rao and Trass (1964) correlated Sh to Re by the equation:

$$
\mathrm{Sh}=1.3 \operatorname{Re}^{0.84}\left(x / \mathrm{d}_{\mathrm{n}}\right)^{-1.27}
$$

for mass transfer in the wall-jet region and for $x / d_{n} \geq 4.5$.

In the stagnation region, the velocity component normal to the surface is appreciable, and the boundary layer thickness is relatively small, hence higher rates of mass transfer are obtained: 


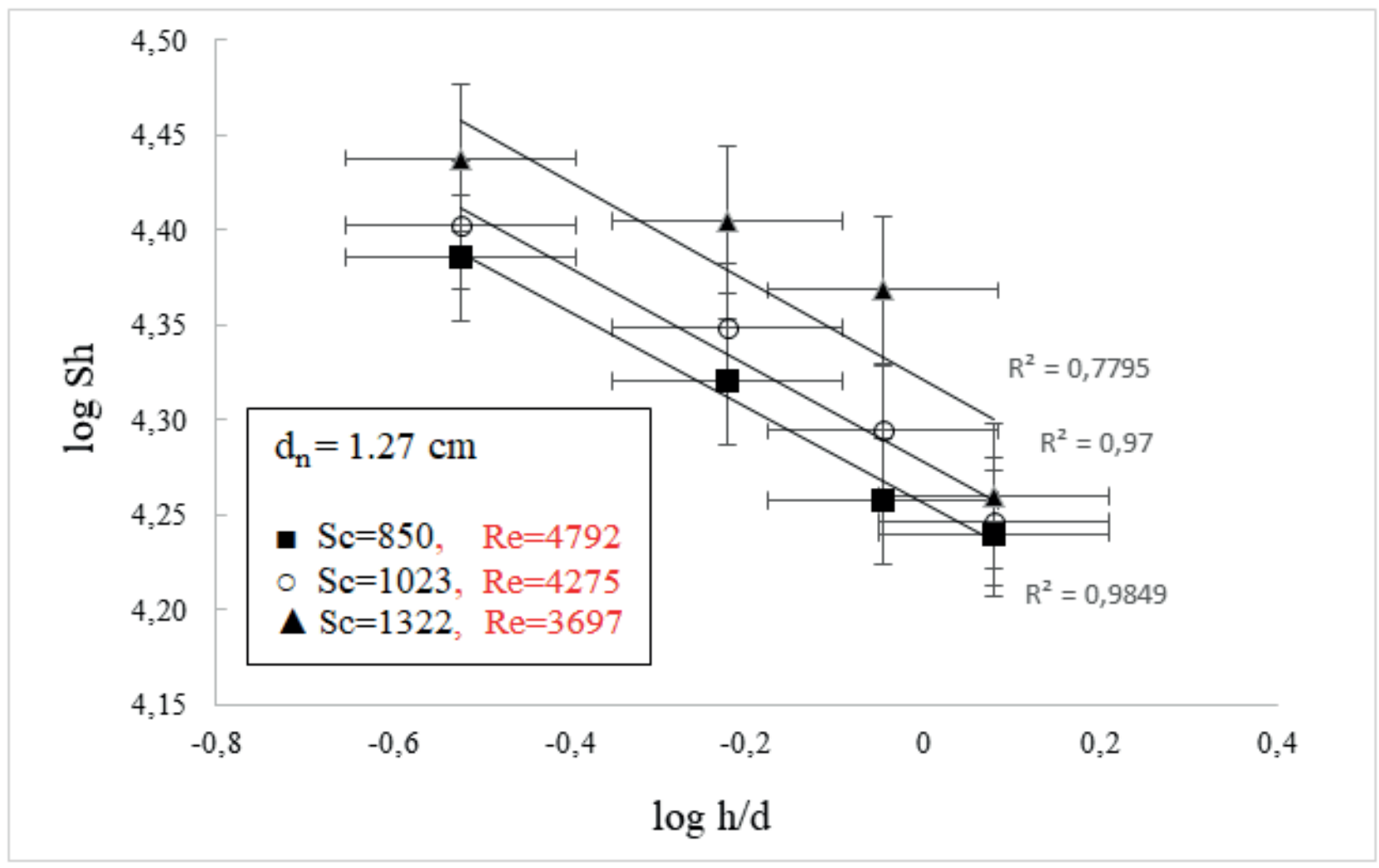

Figure 5. Effect of $\log (\mathrm{h} / \mathrm{d})$ on $\log \mathrm{Sh}$ at different Sc values, showing the error bars

$$
\begin{aligned}
& \text { Sh }=0.046 \operatorname{Re}^{1.06}\left(h / d_{n}\right)^{-0.9} \text { For } h / d_{n}<6.5 \\
& \text { Sh }=0.107 \operatorname{Re}^{1.06}\left(h / d_{n}\right)^{-5.1} \text { For } h / d_{n}>6.5
\end{aligned}
$$

The authors studied the mass transfer between an impinging turbulent jet of water and a flat surface where Re number ranged from 25,000 to 125,000 .

Figure 7 shows the surface of the copper disc before and after impingement; it is obvious that the surface of the copper was highly corroded by the jet flow.

\section{Effect of the drag-reducing polymer}

Table 2 shows that the mass transfer coefficient was found to decrease with increasing polymer concentration by an amount ranging from 1 to $13 \%$ depending on the operating conditions. The reduction in the mass transfer coefficient is believed to be related to eddy damping in the buffer layer by the polymer molecules, which leads to increased thickness of the viscous sublayer and the diffusion layer, with consequent increase in the resistance to mass transfer (Schmitt, 1996)

The present finding is consistent with the results of other authors who studied the effect of drag reducing polymers on the rate of diffusion-controlled corrosion for other geometries under turbulent flow conditions and reported a decrease in the rate of diffusion-controlled corrosion.

Zahran and Sedahmed (1998) studied the effect of dragreducing polymers on the rate of flow induced corrosion of copper rotating cylinders in acidified dichromate solution containing Polyox WSR-301 drag-reducing polymer. They found that the rate of corrosion decreased in the presence of Polyox. The inhibition efficiency decreased with increasing acid concentration, and the best efficiency occurred between a Reynolds number of 4500 and 6000, depending on the acid concentration. The maximum observed corrosion inhibition efficiency was about $23 \%$ for an acid concentration of $0.25 \mathrm{M}$. The modest inhibition efficiency observed in the present study compared to the value obtained by Zahran and Sedahmed (1998) may be attributed to the lower proportion of smallscale high-frequency energy dissipating eddies, which are sensitive to polymer molecules in the turbulence spectrum under the present conditions where Re is relatively low.

\section{CONCLUSIONS}

The present work has shown that submerged jet flow is a powerful tool for enhancing the rate of mass transfer at the interface between liquid-solid systems; however, if the surface is corrodible, severe diffusion-controlled corrosion takes place, as revealed by the present work. The rate of corrosion depends on different parameters as shown below: 


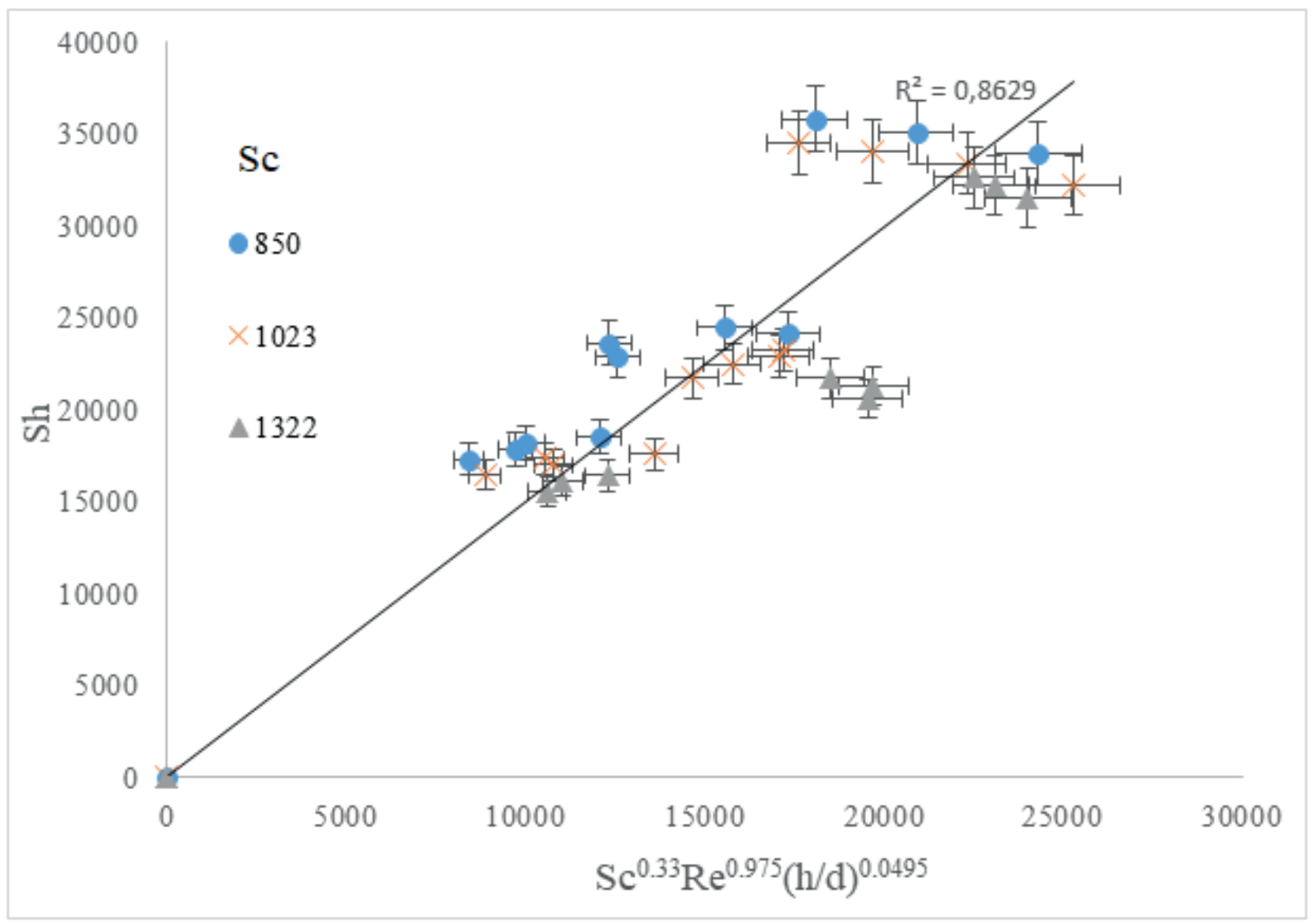

Figure 6. Overall mass transfer correlation, showing the error bars.

a. The rate of diffusion-controlled corrosion of a fixed copper disc under forced jet flow (single phase) is a function of physical properties of the solution $(\rho, \mu, D)$, added to jet nozzle diameter, distance from the jet nozzle to the copper disc surface and solution velocity.

b. The rate of corrosion was found to increase as the solution velocity increases and decreases as jet nozzle inner diameter increases and concentration increases.

c. The rate of mass transfer increases upon decreasing the distance between the nozzle outlet flow point and the surface of copper disc.

d. Liquid-solid mass transfer coefficient is well correlated by the following overall correlation:

$$
\mathrm{Sh}=0.579 \mathrm{Sc}^{0.33} \mathrm{Re}^{0.975}\left(\mathrm{~h} / \mathrm{d}_{\mathrm{n}}\right)^{0.049}
$$

Valid in the range $1852<\mathrm{Re}<5000,850<\mathrm{Sc}<1322$ and $0.3 \leq \mathrm{h} / \mathrm{d} \leq 1.2$.

This equation can be used in practice to design industrial large-scale jet reactors, namely to predict the corrosion allowance of jet stirred tanks, which allows calculation of the bottom thickness required to cover a certain lifetime.

The presence of drag-reducing polymers in the solution was found to reduce the rate of diffusion controlled corrosion of the bottom by an amount ranging from 1 to $13 \%$ depending on polymer concentration . This augments the economic value of using drag-reducing polymers in jet reactors with the dual function of inhibiting corrosion and reducing power consumption.

To confirm and expand the present results, it is recommended to consider the following parameters in future work:

The effect of temperature.

Future studies should use different solutions with different physical properties along with a wider range of experimental conditions including the solution velocity.

The effect of the presence of more than one phase.

The use of pre-corroded surfaces.

The effect of using other types of drag-reducing polymer. 


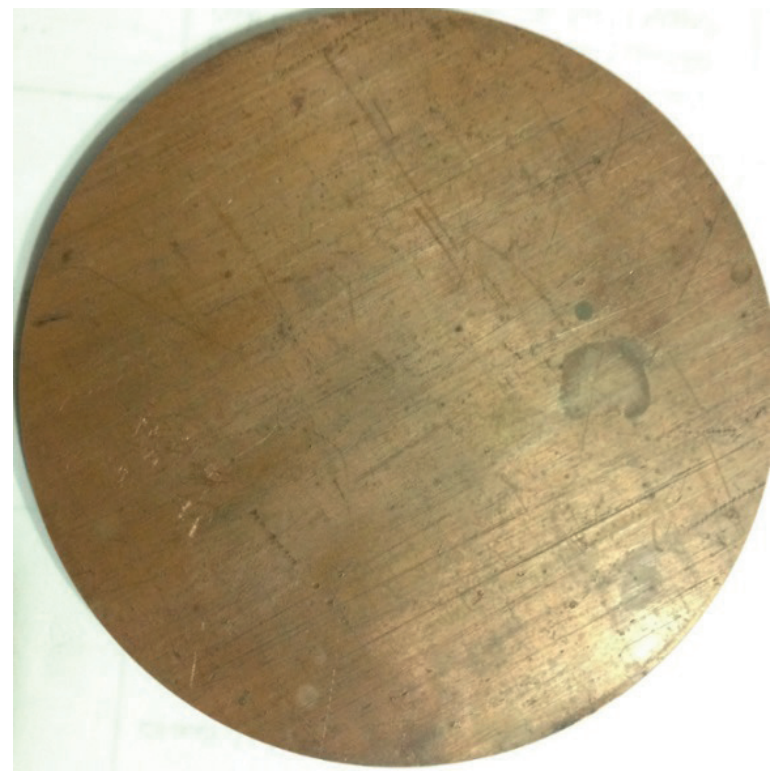

(a)

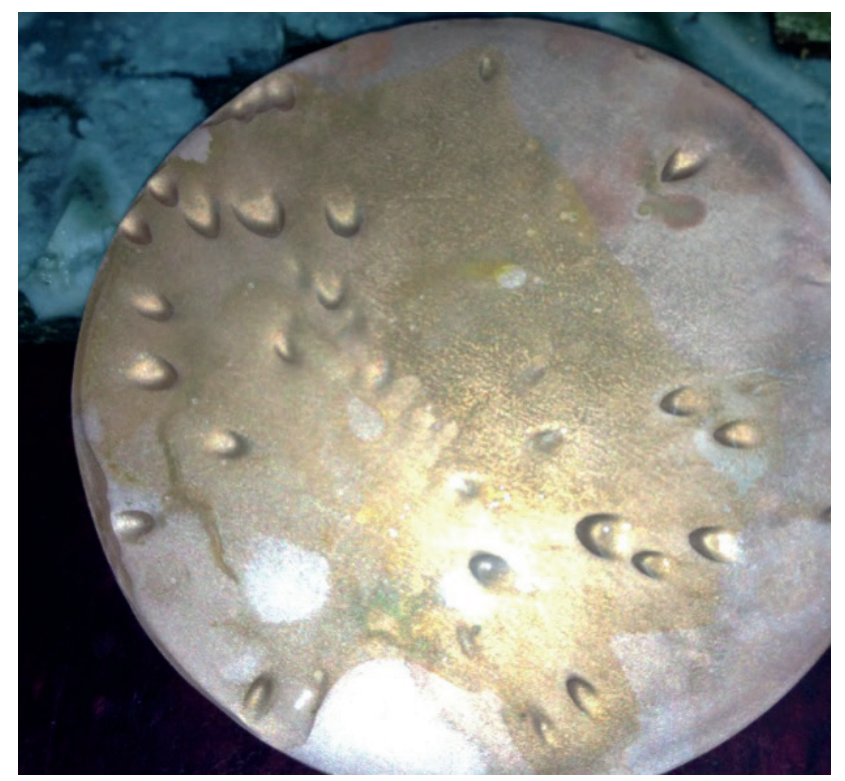

(b)

Figure 7. The surface of the copper disc: (a) before impingement; (b) after impingement

Table 2. Effect of polymer concentration on the inhibition efficiency at different Re

\begin{tabular}{|c|c|c|c|c|c|c|}
\hline \multicolumn{7}{|c|}{ The effect of polymer concentration on the inhibition efficiency at $\mathrm{Re}=4793$} \\
\hline \multirow{2}{*}{$\operatorname{Re}$} & \multicolumn{6}{|c|}{$\%$ decrease in $\mathrm{K}$ ( mass transfer coefficient ) } \\
\hline & Without polymer & 100 ppm & 200 ppm & 300 ppm & 400 ppm & 550 ppm \\
\hline Slope $(\mathrm{cm} / \mathrm{min})$ & 0.061 & 0.06 & 0.059 & 0.058 & 0.055 & 0.053 \\
\hline$(\mathrm{cm} / \mathrm{sec})$ & 0.0259 & 0.0255 & 0.0250 & 0.02461 & 0.0233 & 0.0225 \\
\hline$\%$ decrease in $\mathrm{K}$ & & 1.64 & 3.28 & 4.92 & 9.84 & 13.11 \\
\hline
\end{tabular}

\section{NOMENCLATURE}

a, $\alpha, \beta, \gamma$ - Constants

A - Reaction area, $\mathrm{cm}^{2}$

$\mathrm{C}_{\mathrm{o}}$ - Initial concentration, $\mathrm{mol} / \mathrm{L}$

$\mathrm{C}$ - Concentration at any time $\mathrm{t}, \mathrm{mol} / \mathrm{L}$

$\mathrm{d}$ - Copper disc diameter, $\mathrm{cm}$

$\mathrm{d}_{\mathrm{n}}$ - Nozzle diameter, $\mathrm{cm}$

D - Potassium dichromate solution diffusivity, $\mathrm{cm}^{2} / \mathrm{s}$

$\mathrm{h}$ - Distance between jet nozzle and copper disc

$\mathrm{H}$ - Distance between vertical nozzle and mercury surface, $\mathrm{cm}$

$\mathrm{K}$ - Mass transfer coefficient, $\mathrm{cm} / \mathrm{s}$

1 - Distance between zinc disc and jet nozzle, $\mathrm{cm}$

Q - Volumetric flow rate, $\mathrm{cm}^{3} / \mathrm{s}$

$\mathrm{t}$ - Time, min

$\mathrm{T}$ - Temperature, ${ }^{\circ} \mathrm{C}$

$\mathrm{V}_{\mathrm{n}-}$ Jet liquid velocity

$\mathrm{x}$ - Radial distance from the stagnation point, $\mathrm{cm}$

$\mu$ - Solution viscosity, $\mathrm{g} / \mathrm{cm}$.s

$\rho$ - Solution density, $\mathrm{g} / \mathrm{cm}^{3}$

$\delta$ - Diffusion layer thickness, $\mathrm{cm}$

Re. - Reynolds number $\left(\rho V_{n} d_{n} / \mu\right)$
Sc - Schmidt number $(\mu / \rho D)$

Sh - Sherwood number (Kd/D)

\section{REFERENCES}

Abdel-Aziz, M.H., Mansour, I. A. S. and Sedahmed, G.H., Study of the rate of liquid-solid mass transfer controlled processes in helical tubes under turbulent flow conditions, Chem. Eng. Process., 49, 643-648 (2010).

Alekseenko, S. V., Bilsky, A. V., Dulin, V. M. and Markovich, D. M., Experimental study of an impinging jet with different swirl rates, Int. J. Heat Fluid Flow, 28(6), 1340-1359 (2007).

Bergman, T. L., Lavine, A. S., Incropera, F. P. and Dewitt, D. P., Fundamentals of Heat and Mass Transfer, $7^{\text {th }}$ edition, John Wiley \& Sons Inc., USA (2011).

Cederwall, K., The Initial Mixing on Jet Disposal into a Recipient, Laboratory Investigations, Div. of Hydraulics, Chalmers Univ. of Technology, Goteborg, Sweden, (1953).

Chattopadhyay, H. and Saha, S. K., Turbulent flow and heat transfer from a slot jet impinging on a moving plate, Int. J. Heat Fluid Flow, 24, 685-697 (2003).

Chen, M., Chalupa, R., West, A. C. and Modi, V., High Schmidt mass transfer in a laminar impinging slot jet flow, Int. J. Heat 
Mass Transfer, 43, 3907-3915 (2000).

Chin D. T. and Tsang, C. H., An analysis using the ChiltonColburn analogy for mass transfer to a flat surface from an unsubmerged impinging jet, J. Electrochem. Soc., 125, No. 9, 1461-1470 (1978).

Choo, K., Friedrich, B. K., Glaspell, A. W. and Schilling, K. A., The influence of nozzle to plate spacing on heat transfer and fluid flow of submerged jet impingement, Int. J. Heat Mass Transfer, 97, 66-69 (2016).

Fontana, M. G., Corrosion Engineering, McGraw-Hill, New York (1987).

Gregory, D. P. and Riddiford, A. C., Dissolution of copper in sulphuric acid solutions, J. Electrochem. Soc., 107, 950-956 (1960).

Gruber, R. and Melin, T., Mixed convection in the copper dissolution technique of studying mass transfer, Int. J. Heat Mass Transfer, 46, 2403-2413 (2003).

Ho, C-M. and Nosseir, N. S., Dynamics of an impinging jet. Part1. The feedback phenomenon" J. Fluid Mech., 105, 1191942 (1981).

Hrycak, P., Lee, D.T., Gauntner, W.J., and Livingood, J.N.B., Experimental Flow Characteristics of a Single Turbulent Jet Impinging on a Flat Plate, NASA TN D-5690, 1970.

Kim, N-S. and Giovannini, A., Experimental study of turbulent round jet flow impinging on a square cylinder laid on a flat plate, Int. J. Heat Fluid Fl., 28, 1327-1339 (2007).

Konsowa, A. H., Intensification of the rate of heavy metal removal from wastewater by cementation in a jet reactor, Desalination, 254, 29-34 (2010).

Li, Q., Xuan, Y. and Yu, F., Experimental investigation on submerged single jet impingement using $\mathrm{Cu}$-water nanofluid, Appl. Therm. Eng., 36, 426-433 (2012).

McNaughton, K.J., and Sinclair, C.G., Submerged Jets in Short Cylindrical Flow Vessels, J. Fl. Mech., 25(2), 367-375 (1966).

Pan, Y., Stevens, J. and Webb, B. W., Effect of nozzle configuration on transport in the stagnation zone of axisymmetric, impinging free surface liquid jets: Part 2-local heat transfer, J. Heat Transfer-T. ASME, 114, 880-886 (1992).

Pickett, D. J., Electrochemical Reactor Design, Elsevier, New York (1977).

Rao, V. V. and Trass, O., Transfer from a Flat Surface to an Impinging Turbulent Jet, Can. J. Chem. Eng., 42, 95-99 (1964).

Sagot, B., Antonini, G., Christgen, A. and Buron, F., Jet impingement heat transfer on a flat plate at a constant wall temperature, Int. J. Therm. Sci., 47, 1610-1619 (2008).

Şara, O. N., Erkmen, J., Yapici, S. and Çopur, M., Electrochemical mass transfer between an impinging jet and a rotating disk in aconfined system”, Int. Commun. Heat Mass Transfer, 35, 289-298 (2008).
Schmitt, G. Drag reduction - an important contribution to the protective action of corrosion inhibitors and surfactants in corrosive flow system, fourth international workshop on electrochemical, flow measurements fundamentals and applications, Lahnstein, Germany, March 1996.

Sedahmed, G. H., Abdo, M. S. E., Amer, M. and Abd E1Latif, G., Mass Transfer at a Pipe Inlet Zone In Relation To Impingement Corrosion Int. Commun. Heat Mass Transfer, 25, 443-451 (1998).

Sedahmed, G. H., Abdo, M.S., Hassan, M.S. and Konsowa A.H., Intensification of mass transfer controlled processes at the interface between two immiscible liquids by an axial turbulent submerged jet, Chem. Eng. Process., 46, 10-16 (2007).

Sellin, R. H., Hoyt, J. W. and Scrivener, O., The effect of drag reducing additives on fluid flows and their industrial application. Part 1: Basic aspects, J. Hydr. Res., 20, 29-68 (1982).

Sellin, R. H., Hoyt, J. W. and Scrivener, O., The effect of drag reducing additives on fluid flows and their industrial application. Part 2: Present applications and future proposals, J. Hydr. Res., 20, 235-292 (1982).

Sherwood, T. K., Pigford, R. L. and Wilke, C. R., Mass transfer, McGraw Hill, New York (1975).

Shi, Z-H., Li, W-F., Du, K-J., Liu, H. and Wang, F-C., Experimental study of mixing enhancement of viscous liquids in confined impinging jets reactor at low jet Reynolds numbers, Chem. Eng. Sci., 138, 216-226 (2015).

Shuja, S. Z., Yilbas, B. S. and Budair, M. O., Influence Of Conical And Annular Nozzle Geometric Configurations On Flow And Heat Transfer Characteristics Due To Flow Impingement Onto A Flat Plate", Numer. Heat Transfer, Part A, 48, 917939 (2005).

Sydberger, T. and Lotz, U., Relation between Mass Transfer and Corrosion in a Turbulent Pipe Flow, J. Electrochem. Soc., 129, 276-283 (1982).

Vickers, J.M.F., Heat Transfer Coefficients between Fluid Jets and Normal Surfaces, Ind. Eng. Chem., 51:8, 967-972 (1959).

Vogel, A. I., Text Book of Quantitative Analysis, Longman, London (1961).

Webb, B. W. and Ma, C. F., Single-phase liquid jet impingement heat transfer, Adv. Heat Transfer 26, 105-217 (1995).

Wen, M-Y. and Jang, K-J., An impingement cooling on a flat surface by using circular jet with longitudinal swirling strips, Int. J. Heat and Mass Transfer, 46, 4657-4667 (2003).

Zahran, R. R.and Sedahmed, G. H., Effect of drag-reducing polymers on the rate of flow-induced corrosion of metals, Mater Lett, 35, 207-213 (1998).

Zheng, Q., Ma, C. F., Zhuang, Y. and Lei, D. H., Local characteristics of recovery factor and heat transfer coefficient with impinging free-surface jets of large Pr number liquid, J. Eng. Thermophys., 18, 217-220 (1997). 